\title{
NEW CATIONIC VESICLES PREPARED WITH DOUBLE CHAIN SURFACTANTS FROM ARGININE: ROLE OF THE HYDROPHOBIC GROUP ON THE ANTIMICROBIAL ACTIVITY AND CYTOTOXICITY
}

A. Pinazo ${ }^{1}$, V. Petrizelli ${ }^{4}$, M. Bustelo ${ }^{1}$, R. Pons ${ }^{1}$, M.P. Vinardell ${ }^{2}$, M. Mitjans ${ }^{2}$, A. Manresa $^{3}$, L. Perez ${ }^{1 *}$

\footnotetext{
${ }^{1}$ Department of Chemical and Surfactant Technology, IQAC, CSIC, C/JordiGirona 18-26, 08034, Barcelona, Spain

${ }^{2}$ Departament of Physiology, Facultat de Farmàcia, Universitat de Barcelona, Av. Joan XIII s/n, 08028, Barcelona, Spain

${ }^{3}$ Departament of Microbiology, Facultat de Farmàcia, Universitat de Barcelona, Av. Joan XIII s/n, 08028, Barcelona, Spain

${ }^{4}$ While in Department of Chemical and Surfactant Technology, IQAC, CSIC
}

*Corresponding author:

Lourdes Pérez Muñoz

C/JordiGirona 18-26, 08034, Barcelona, Spain

Tf : (+34) 934006164

Fax: (+33) 34932045904

E-mail: lourdes.perez@cid.csic.es

\section{Statistical Summary}

Number of words: 5929

Number of tables: 4

Number of figures: 4 
Table of contents graphic
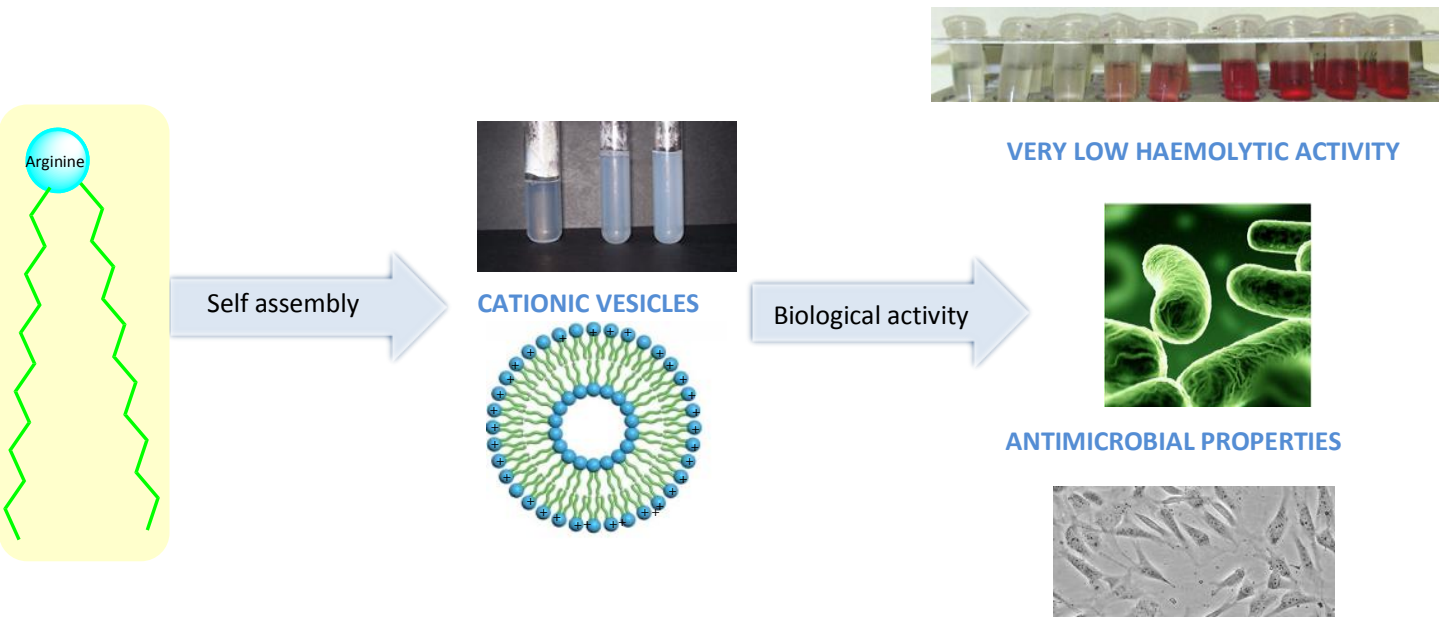

MODERATE CYTOTOXICITY 


\section{ABSTRACT}

Cationic double chain surfactants have attracted much interest because they can give rise to cationic vesicles that can be used in biomedical applications. Using a simple and economical synthetic approach, we have synthesized four double-chain surfactants with different alkyl chain lengths $\left(\mathrm{LANHC}_{\mathrm{x}}\right)$. The critical aggregation concentration of the double chain surfactants is at least one order of magnitude lower than the CMC of their corresponding single-chain LAM and the solutions prepared with the $\mathrm{LANHC}_{\mathrm{x}}$ contain stable cationic vesicles. Encouragingly, these new arginine derivatives show very low haemolytic activity and weaker cytotoxic effects than conventional dialkyl dimethyl ammonium surfactants. In addition, the surfactant with the shortest alkyl chain exhibits good antimicrobial activity against Gram-positive bacteria. The results show that a rational design applied to cationic double chain surfactants might serve as a promising strategy for the development of safe cationic vesicular systems.

Keywords : cationic vesicles, arginine-based surfactants, antimicrobial activity, cytotoxicity 


\section{INTRODUCTION}

Development of dialkyl cationic surfactants has attracted considerable interest because of their use in biomedical applications [1]. Due to their molecular geometry, these types of amphiphiles give rise to niosomes with a cationic charge that can be used as drug delivery systems or gene therapy [2]. These therapeutic applications require the use of stable surfactants under sterilization conditions that present low haemolytic or cytotoxic activity. Several cationic lipids such as DOTMA (1,2-di-O-octadecenyl-3trimethylammonium propane) or DOTAP (1,2-dioleoyl-3-trimethylammonium-propane) have been used to prepare cationic niosomes for pharmaceutical applications [3], but the production of such lipids on a large scale is very expensive. Alternatively, dialkyl dimethyl ammonium bromide surfactants can be prepared at reasonable cost and these surfactants also form cationic niosomes and show antimicrobial activity [4]. However, their use is seriously questioned from an environmental point of view as quaternary ammonium surfactants are toxic to aquatic organisms and not biodegradable [5-6-7].

In general, quaternary ammonium surfactants are more toxic than surfactants with the cationic charge delocalized in a heterocyclic ring or guanidine group [8]. Over the last years, our research group has studied $\mathrm{N}$-acyl arginine derivative surfactants that consist of one alkyl chain linked to the $\alpha$-amino group of the arginine methyl ester. These surfactants present physicochemical properties similar to those of classic cationic surfactants, but they show high biodegradability, low toxicity against aquatic microorganisms and moderate toxicity against human cell lines. Additionally, these compounds can be easily prepared from renewable raw materials [9].

In this work, we have prepared new double-chain cationic surfactants from arginine using the single-chain $\mathrm{N}^{\alpha}$-lauroyl-arginine methyl ester (LAM) as starting material (Figure 1). The new compounds consist of one arginine as the cationic polar head and two alkyl chains linked to the arginine through amide bonds (Figure 1). For the newly prepared 
surfactants, we have studied the micellization process, their ability to form cationic niosomes in water solutions as well as the size distribution and zeta potential of the cationic vesicles. Moreover, their antimicrobial activity and cytotoxicity have been determined in order to explore their potential applications. This work may represent a step forward in the development of non-toxic and stable colloidal systems to be used in pharmaceutical applications.

\section{MATERIALS AND METHODS}

This section briefly describes the methods used in this work, and more details are reported as supplementary information.

The progress of the reactions as well as the purity of the final compounds was monitored by HPLC, Merck-Hitachi D-2500 model using a UV-VIS detector L-4250 at $215 \mathrm{~nm}$. The structures of the pure compounds were examined by ${ }^{1} \mathrm{H}$ and ${ }^{13} \mathrm{C}$ nuclear magnetic resonance analyses, recorded on a Varian spectrometer at $499.803\left({ }^{1} \mathrm{H}\right)$ and $125.233\left({ }^{13} \mathrm{C}\right)$ $\mathrm{MHz}$, respectively. Chemical shifts $(\delta)$ are reported in parts per million (ppm) downfield from tetramethylsilane (TMS). Mass spectroscopy (MS) spectra with fast atom bombardment (FAB) or electrospray techniques were carried out with a VG-QUATTRO from Fisons Instruments. (S.I.2 and S.I.3)

\section{Conductivity}

Conductivity was measured using an Orion Cond. Cell 011010A with platinized platinum electrodes in conjunction with a Thermo Orion 550A with a cell constant of $0.998 \mathrm{~cm}^{-1}$. Samples for conductivity measurements were prepared by weight in Millipore ultra-pure water.( S.I.3.)

\section{Surface tension}

The surface tension was measured using a home-made pendant drop surfactometer. A surfactant solution drop is created at the end of a straight cut Teflon tube with a $0.8 \mathrm{~mm}$ 
internal diameter and a $1.58 \mathrm{~mm}$ external diameter The image of the drop is taken using a web cam. The image is corrected for spherical aberration. The droplet contour is taken at the point of maximum intensity slope. This contour is fitted to the Laplace -Young equation [10] using a Golden Section Search Algorithm that has the centre coordinates, an angular correction for the vertical alignment, the radius of the droplet and the interfacial tension as parameters.

\section{Vesicles preparation}

Surfactants, adequately weighed, were dissolved in methanol. The organic solvent was vacuum dried and the resulting lipid film was hydrated under sonication (30 minutes at $50^{\circ} \mathrm{C}$ ) with deionized water (Table 1 ).

\section{TABLE 1}

\section{Size distribution and $\zeta$-potential}

The $\zeta$-potential of the formulations was measured by laser Doppler electrophoresis using the Zetasizer 2000 (Malvern Instruments Ltd., Malvern, U.K.), at $25^{\circ}$ C. Analyses were done in triplicate.

Dynamic Light Scattering (DLS) was used to measure the size distribution of all formulations. The DLS unit was a Malvern Zeta Nanosizer, working at $632.8 \mathrm{~nm}$ and $25^{\circ} \mathrm{C}$. The scattering intensity was measured at a $173^{\circ}$ angle to the incident beam [11]. At least 10 runs were performed for each sample. The measured correlation was used to calculate the size distribution. The size distribution profile was determined with the CONTIN algorithm [12] which allows working with monomodal as well as multimodal distributions.

\section{Antimicrobial activity}

\section{a) MIC determinations}


Antimicrobial activity was determined "in vitro" on the basis of the minimum inhibitory concentration (MIC) [13], defined as the lowest antimicrobial agent concentration that inhibits the development of visible growth after incubation at $37^{\circ} \mathrm{C}$ for 24 hours (S.I.5).

\section{Cytotoxicity evaluation}

Cell line cultures. 3T3 (murine Swiss albino fibroblasts), HaCaT (spontaneously immortalized human keratinocytes) and human epithelial cervical cancer HeLa cell lines (Eucellbank, Barcelona).

Chemical exposure. Stock solutions of surfactants were prepared in DMSO at a maximum concentration of $10 \mathrm{mg} / \mathrm{mL}$. Serial dilutions were subsequently prepared in DMEM (Dulbecco's Modified Eagle's Medium) supplemented with 5\% FBS (phosphate buffer saline), $2 \mathrm{mM}$ L-glutamine, and $1 \%$ antibiotic solution (final concentration of DMSO in culture medium $<1 \%$ ). After removal of the medium culture, 3T3, HaCaT or HeLa cells were exposed to the surfactants in multi-well plates. Controls containing only culture medium were included in each plate, and they were independent for each of the different surfactants tested. Plates were incubated at $37^{\circ} \mathrm{C}, 5 \% \mathrm{CO}_{2}$ for 24 hours.

The cytotoxicity of surfactants against these three cell lines was determined using a tetrazolium-based assay (MTT) [14] and the NRU assay. (S.I.6)

Haemolysis assay. We followed an adaptation of the method described by Pape et al. [15]. ( S.I.6)

\section{Synthesis}

Synthesis of $\mathrm{LANHC}_{n}$. 0.0035 moles of LAM, synthesized as reported in the literature [16], were weighed into a round flask. Then 0.014 moles of the corresponding fatty amine were added. The mixture was heated to the melting point of the amine and was stirred at this temperature for three hours. After the completion of the reaction, the mixture was cooled at room temperature and several crystallizations in methanol/acetonitrile were 
carried out to remove the excess of fatty amine. The identification of the products was performed by HPLC, ${ }^{1} \mathrm{HNMR}$ and ${ }^{13} \mathrm{CNMR}$, Mass Spectroscopy and Elemental analysis (Supporting Information)

\section{RESULTS AND DISCUSSION}

Cationic vesicles have great potential in new biomedical applications. They can be used as antimicrobial systems, in gene delivery and as vesicles for drugs. The aim of this work is to design and synthesise new biocompatible surfactants that give rise to nontoxic cationic vesicles in the aqueous medium.

\section{Synthesis}

Surfactants based on renewable raw materials are characterized by their low negative impact on the environment. In this work, we have prepared one single-chain surfactant and four double-chain surfactants using renewable resources and a clean and rapid synthetic methodology.

The LAM can be classified as biocompatible and biodegradable due to its biological properties. It has been synthesized following the procedure previously reported by us. [9]. The compounds with two alkyl chains were obtained by simply heating the LAM with the corresponding amine without using any solvent (Figure 1). In these conditions, the percentage of conversion is always higher than $90 \%$ after 2 hours and the reaction does not require the use of any activating agent. This approach allowed us to perform the synthesis in a short time and on a large scale and at a reasonable cost.

These cationic double chain surfactants have amide linkages between the polar head and the hydrophobic chains. Usually, the introduction of an ester or amide linkage between the alkyl chain and the hydrophilic moiety improves the biodegradation of surfactants [17].

\section{FIGURE 1}




\section{Critical aggregation concentration}

The concentration at which the surfactant molecules start to form aggregates in aqueous solutions was determined by tensiometry and conductivity. The $\mathrm{LANHC}_{\mathrm{x}}$ surfactants are sparingly soluble in water; therefore, the most concentrated samples had to be prepared by sonication of the aqueous solution during 10 minutes at $45^{\circ} \mathrm{C}$. All samples give rise to bluish solutions, indicating the presence of big aggregates. Previous studies showed that the single-chain LAM formed transparent solutions that contained spheroidal micelles [18]. The critical packing parameter (CCP) considers the geometry of the molecule to predict what type of structures can be formed when monomers start to aggregate [19]. Usually, double-chain surfactants have a cylindrical shape with CPP values between 0.5 and 1 . This shape explains why these surfactants have low spontaneous curvature and tend to form planar structures like lamellar bilayers and vesicles while the conically shaped single-chain surfactants form spherical micelles. According to the above considerations, the surfactants studied in this work are expected to form vesicles or big aggregates, therefore the concentration at which these surfactants start to form aggregates in solution will be denoted as the critical aggregation concentration (CAC).

\section{TABLE 2}

The surface tension/concentration plots show only one breakpoint in the $0.01-0.1 \mathrm{mM}$ concentration range corresponding to the $\mathrm{CAC}$ values (Table 2). These results suggest that vesicles are formed directly at low concentrations. Double chain surfactants that form micelles and vesicles show two transition points in the surface tension curves [20]. It has been reported that surfactants with one arginine or lysine and two alkyl chains also form vesicles in aqueous solutions [21]. The didodecyl dimethylammonium bromide, a widely 
studied double chain cationic, forms lamellar bilayers or vesicles, and the critical aggregation is denoted as CVC (critical vesicular concentration) [22-23-24].

The incorporation of the second alkyl chain into the LAM enhances the hydrophobic character of the molecule and consequently causes a significant decrease of the CAC (Table 2). The difference in the CAC between $\mathrm{LANHC}_{12}$ and LAM is more than one order of magnitude. The CAC of gemini surfactants from arginine with two alkyl chains of twelve carbon atoms is also higher than that found for these double-chain derivatives. Para et al. [25] also found that the surface activity of the gemini surfactant was somewhere in between the surface activity of the monomeric and that of the dimeric surfactant.

The CAC in aqueous medium varies little with the change in alkyl chain length of one of the hydrophobic chains. First, the CAC slightly decreases from $n=10$ to $n=14$ and then it rises for $n=18$. For single-chain ionic surfactants, the CAC decreases abruptly as the number of carbon atoms in the hydrophobic group increases. However, for very hydrophobic surfactants the CAC does not decrease so rapidly with increase in the length chain, and when the chain exceeds 18 carbons, it may remain substantially unchanged [26] The presence of a carbon-carbon double bond in LANHC $_{18}$ gives rise to a bulky hydrophobic group. The increase of the CAC is probably due to the difficulty of incorporating the bulky hydrophobic group in the interior of the micelle.

Table 2 also contains the effectiveness of these surfactants in decreasing the surface tension of water $(\pi)$ as well as the minimum area per molecule at the interface ( $\left.A_{m}\right)($ S.I.4). Double chain surfactants are more effective reducing the surface tension than the singlechain LAM. The presence of two alkyl chains results in close packing at the interface and consequently the surface tension at the CAC decreases. Among the $\mathrm{LANH}_{\mathrm{x}}$ compounds, the effectiveness decreases by increasing the length of one alkyl chain. The $A_{\min }$ of the 
double-chain derivatives is similar to that of LAM. This suggests that, due to the presence of two hydrophobic chains, the LANHCx compounds are tightly packed at the interface.

\section{FIGURE 2}

The curve of conductivity against surfactant concentration at 25 and $50{ }^{\circ} \mathrm{C}$ for $\mathrm{LANHC}_{14}$ is shown in Figure 2. Similar curves have been obtained for the other surfactants, and the CAC values obtained at both temperatures are included in Table 2. The CAC of LANHC 18 was measured by conductivity at $50{ }^{\circ} \mathrm{C}$ only since it was difficult to achieve stable values of conductivity at $25{ }^{\circ} \mathrm{C}$. Only one breakpoint was detected in all cases confirming that these surfactants form big aggregates directly. Moreover, the temperature does not affect the $\mathrm{CAC}$ values. The CAC values obtained by conductivity are slightly higher than those obtained by surface tension measurements. The discrepancy between surface tension measurements and determinations by bulk techniques to obtain the $\mathrm{CMC} / \mathrm{CAC}$ is present in the literature. [27-28].

\section{Cationic vesicles prepared with double chain arginine surfactants}

In this work we have explored the capability of cationic dialkyl arginine derivatives to form vesicles. These aggregates were prepared following the procedure described in the experimental section.

After preparation, vesicles were left for 3 hours at room temperature and then the diameter and size distribution was measured at $25^{\circ} \mathrm{C}$ using dynamic light scattering measurements (DLS). All solutions were then heated again for 60 minutes at $50^{\circ} \mathrm{C}$ and the diameter and size distribution were evaluated at $50^{\circ} \mathrm{C}$. Afterwards, the formulations were kept at room temperature for 6 months.

\section{FIGURE 3}


The image in Figure 3 shows the dispersions at three different concentrations (1, 2.5 and $5 \mathrm{~mm})$. The samples' visual appearance provides valuable information. It is known that a change in the turbidity of a surfactant solution can be related to the change in the amount and/or the size of the aggregates. The $\mathrm{LANHC}_{10}$ forms a bluish translucent solution at 1 $\mathrm{mM}$. By increasing the concentration, the solutions became milky and turbid (Figure 3). All solutions of $\mathrm{LANHC}_{12}$ appeared as bluish and viscous dispersions with the typical aspect of vesicular formation. The appearance of $\mathrm{LANHC}_{14}$ solutions is similar to those based on $\mathrm{LANHC}_{12}$, with a slight intensification of turbidity. After the second heating cycle, all samples appear less turbid. Finally, some evidence of phase separation has been observed after 1 month for the most concentrated samples of LANHC $_{10}$ and after 2 months for the $\mathrm{LANHC}_{10} 1 \mathrm{mM}$ solution. Formulations based on $\mathrm{LANHC}_{12}, \mathrm{LANHC}_{14}$ and $\mathrm{LANHC}_{18}$ remained stable for 6 months.

\section{TABLE 3}

Table 3 shows the particle size and size distribution data obtained for LANHC $_{\mathrm{x}}$ based formulations and Figure S1 (Supporting information) shows the size distribution profiles. At room temperature, $\mathrm{LANHC}_{10}$ solutions contain large vesicles (diameters $>1000 \mathrm{~nm}$ ) and at $50^{\circ} \mathrm{C}$ the diameter of the aggregates is still high. At room temperature $\mathrm{LANHC}_{12}$ solutions show high polydispersity and contain giant vesicles (diameters >1000 nm). However, at $50^{\circ} \mathrm{C}$ these samples show only one peak with an average diameter in the range 150-300 nm. Samples based on $\mathrm{LANHC}_{14}$ show a very similar behaviour. However, the sample prepared with $\mathrm{LANHC}_{18}$ at $1 \mathrm{mM}$ is a translucent solution that contains small aggregates (about $60 \mathrm{~nm}$ ) at 25 and $50{ }^{\circ} \mathrm{C}$. From the results, it is not possible to establish how the alkyl chain length affects the vesicle's size. For $1 \mathrm{mM}$ samples, the vesicle's size decreases as the alkyl chain increases, especially for $n=18$. However, the more concentrated formulations appear not to follow this trend. 
These results correlate well with the stability of samples. Formulations that contain very large vesicles show phase separation after 1 or 2 months while those that contain medium size vesicles remain stable for more than 6 months. The stability can also be related to the repulsive interactions among aggregates with positive charges. As expected, large positive $\zeta$-potential values have been obtained for vesicles prepared with these surfactants (61.4 $\mathrm{mV}$ for $\mathrm{LANHC}_{10}, 48.3 \mathrm{mV}$ for $\mathrm{LANHC}_{12}, 36.6 \mathrm{mV}$ for $\mathrm{LANHC}_{14}$ and 18 for LANHC $_{18}$ ). The positive charge density of the aggregates is strong enough to ensure that no coagulation occurs for $\mathrm{LANHC}_{12}, \mathrm{LANHC}_{14}$ and $\mathrm{LANHC}_{18}$ formulations. In the case of $\mathrm{LANHC}_{10}$ the large sizes observed can result in large van der Waals attractive forces between vesicles that allow these aggregates to overcome the repulsive electrostatic forces and induce phase separation. It has been described that vesicles prepared with mechanical forces, like ultrasonication, are metastable. ${ }^{29}$ For example, sonicated DDAB vesicles with high z potentials were unstable, resulting in phase separation [30]. However, when the size of these DDAB vesicles is reduced, the aggregates are stable for extended periods of time as a result of repulsive electrostatic forces.

The preparation procedure also can strongly affect the size of the vesicle. Different vesicle sizes have been reported for the same compound. Feitosa el al. reported DDAB vesicles prepared at room temperature with a diameter of $195 \mathrm{~nm}$ [31]. For DDAB and dioctadecyl dimethylammonium bromide (DODAB) the diameters of spontaneously formed vesicles were $70 \mathrm{~nm}$ [32] and $674 \mathrm{~nm}$ [33] respectively. After bath sonication of the dispersion, the diameter of the DODAB vesicles dropped to $44 \mathrm{~nm} \mathrm{[34],} \mathrm{and} \mathrm{to} 66 \mathrm{~nm}$ after tip sonication [35]. Kondo el al. [30] showed that the DDAB vesicles' diameter decreased with ultrasonication time, reaching a limiting value of approximately $17 \mathrm{~nm}$ after about $1.5 \mathrm{~h}$. 
To summarize, it can be stated that these compounds form large and stable vesicles at room temperature. The size of niosomes formulated with these compounds exhibits strong temperature dependence. DLS measurements at $25^{\circ} \mathrm{C}$ show a major population of very big aggregates in the micrometre range with a large polydispersity. When heated to $50{ }^{\circ} \mathrm{C}$ the polydispersity, as well as, the size of the aggregates decrease drastically. This behaviour could be due to the state of the niosomes. In general, vesicular dispersions scatter more light in the gel than in the liquid-crystalline state owing to formation of large or more complex vesicular structures [31].

\section{Antimicrobial activity}

In this work, we have evaluated how the incorporation of a second alkyl chain affects the antimicrobial activity of LAM [16]. Table 4 shows that the antimicrobial activity of these new surfactants is lower than that of LAM, probably due to their high hydrophobicity. The low antimicrobial activity of the new surfactants can also be related to their aggregation behaviour. For LAM the MIC values occur at concentrations below the CMC. Therefore, monomers are the species that interact with the cells. However, the aggregation of $\mathrm{LANHC}_{\mathrm{x}}$ takes place at very low concentrations, and they form vesicles instead of micelles. Hence, in this case, the vesicles have to interact with the cellular membranes. Recent studies have shown that for colloidal suspensions prepared with arginine-based gemini surfactants the antimicrobial and haemolytic activity increases as the aggregate's size decreases [36]. Vieira et al. who studied the antimicrobial and haemolytic activity of DODAB (dioctadecyl dimethylammonium bromide) bilayer fragments and DODAB large vesicles and also found that small aggregates penetrate more deeply into the cell surface, and, consequently have lower $\mathrm{MIC}$ and $\mathrm{HC}_{50}$ values [37]. It has also been reported that niosomes containing monoalkyl surfactants from methylprolinolinium show 
good antimicrobial activity while niosomes formulated with the dialkyl homologue do not show biological activity. These authors suggested that the lateral homogeneity of the niosomes' bilayer could be another important parameter that controls their biological activity [38-39]. Whereas niosomes prepared with single chain surfactants had Tm values around $27{ }^{\text {a }} \mathrm{C}$, double chain cationic surfactants gave rise to niosomes with a high $\mathrm{Tm}(40$ $\left.{ }^{\circ} \mathrm{C}\right)$. Therefore, at $37^{\circ} \mathrm{C}$ the single chain surfactants are in the LC phase while the double chain ones are in the solid ordered phase, and the bilayers have poor lateral miscibility.

\section{TABLE 4}

The antimicrobial activity of these new surfactants depends on hydrophobicity, although the correlation between hydrophobicity and antimicrobial activity is not linear. The LANHC $_{10}$, the less hydrophobic and most active surfactant, shows antimicrobial activity against most of the microorganism tested. However, the $\mathrm{LANHC}_{12}$ and $\mathrm{LANHC}_{14}$ show a moderate activity only against Gram-positive bacteria and $\mathrm{LANHC}_{18}$ did not show activity against any of the microorganisms.

As expected, Gram-negative bacteria were more resistant than Gram-positive bacteria. These bacteria have a hydrophilic surface due to the side chains of the LPS which hinders hydrophobic molecules from entering the bilayer [40].

\section{Cytotoxicity}

The concentration that induces haemolysis of $50 \%$ of the erythrocytes $\left(\mathrm{HC}_{50}\right)$ was determined and quantified from plots of percentage of haemolysis as a function of surfactant concentration.

The low haemolytic activity of $\mathrm{LANHC}_{10}, \mathrm{LANHC}_{12}$ and $\mathrm{LANHC}_{14}$ is noteworthy (Table 5). For cationic surfactants, these $\mathrm{HC}_{50}$ concentrations are exceptionally high. The surface of red blood contains negative charges, which prevents their self-aggregation and 
makes them as colloids suspended in blood [41]. For this reason, cationic surfactants can interact well with the negatively charged surface of erythrocytes.

\section{TABLE 5}

Compared with the LAM, $\left(\mathrm{HC}_{50}=144 \mu \mathrm{M}\right)$ [42] the haemolytic activity of these compounds is exceptionally low (Table 5). This could be ascribed to the size and stability of the aggregates that they form. Notice that, except the $\mathrm{LANHC}_{18}$, all $\mathrm{LANHC}_{\mathrm{x}}$ surfactants form large and stable giant vesicles at $25^{\circ} \mathrm{C}$. In general, single-chain surfactants are less haemolytic than the corresponding double-chain surfactants with a gemini structure [43]. However, the haemolytic character of gemini surfactants from arginine with alkyl chains of 12 carbon atoms and long spacer chains is considerably lower than that of LAM, probably due to the small size of the gemini aggregates [36]. Carmona-Ribeiro et al. also found that solutions of the single chain derivative hexadecyl trimethylammonium bromide $\left(\mathrm{HC}_{50}=0.7 \mu \mathrm{M}\right)$ are more haemolytic than those of large vesicles formed by the double-chain compound dioctadecyl dimethylammonium bromide $\left(\mathrm{HC}_{50}=4.0 \mu \mathrm{M}\right)[37]$.

It should also be considered that the vesicles' stability can also affect their haemolytic character. It has been described that haemolysis was induced immediately after the addition of dialkyl dimethylammonium surfactants with relatively short alkyl chains (10 carbon atoms) while haemolysis was gradually induced for long alkyl chains (16 and 18 carbon atoms). This behaviour was ascribed to the stability of the vesicles formed by these compounds. Haemolysis is induced by the penetration of the monomer into the erythrocyte membrane. Vesicles of dialkyl dimethylammonium with short chains appear unstable and may easily become monomers. However, dialkyl dimethylammonium surfactants with long hydrophobic chains form more stable vesicles or aggregates, 
because of that the presence of monomers was reduced and haemolytic activity decreased [44].

The haemolytic activity of these surfactants increased considerably by increasing the length of the second alkyl chain. The influence of the hydrophobic domain (alkyl chain length and number of hydrophobic chains) on cellular toxicity is not well established in the literature. There are some surfactant analogues in which haemolysis increases with the elongation of the alkyl chain [45-46] whereas, in other groups, haemolysis decreases as the alkyl chain increases [47]. Fogt et al. [48] and Lv et al. [8] also reported that for aliphatic chains, single-chain cationic lipids are more toxic and less efficient than their double-chain counterparts whereas Tang and Hughes [49] demonstrated that the singlechain 6-lauroxyhexyl ornithinate presented lower cytotoxicity than DOTAP, a doublechain cationic surfactant widely used in gene therapy. It is, therefore, essential to accurately characterize the physicochemical and biological properties of new surfactants to obtain data that allow correlating results with toxic effects and help to develop novel and safe cationic lipids.

To summarize, it can be stated that the haemolytic activity of LAM [42] is lower than that of standard monoQuat surfactants with comparable CMC values and the haemolytic character of gemini surfactants from arginine with long spacer chains [36] is much lower than that of bis(Quats) gemini surfactants [50] or gemini surfactants based on pyridinium salts [51]. Our results also indicate that the haemolytic activity of arginine-based double chain surfactants is also much lower than that of double chain surfactants with the cationic charge on a quaternary ammonium [37]. Then it can be concluded that for similar chemical structures, cationic surfactants from arginine, in which the cationic charge is located on the guanidine group, are less haemolytic than QUATS. 
The cytotoxic effects of these surfactants were evaluated with 3T3, HaCaT and HeLa cells using two different endpoint assays (Table 5). The combination of different cell lines and cytotoxicity assays gives information concerning general and specific toxicological mechanisms [52].

All these cationic surfactants induced a clear dose-response relationship, which allowed us to determine the half maximal inhibitory concentration or $\mathrm{IC}_{50}$. The toxicity depends on both the cell line tested and the end point assay. HaCat, 3T3 and HeLa cells are much more fragile than red blood cells to the vesicles formed by these surfactants. Moreover, the $\mathrm{IC}_{50}$ values obtained using the MTT assay are lower than those obtained with the NRU assay. These differences can be ascribed to the cytotoxicity mechanisms evaluated by the different biological assays. Haemolysis depends on the interaction of surfactants with the plasma membrane of a cell. The MTT assay is a measurement of cellular metabolic activity within the mitochondrial compartment while the NRU assay measures membrane integrity. Taking into account the cell damage evaluated by every assay, our results suggest that the aggregates formed by the $\mathrm{LANHC}_{\mathrm{x}}$ derivatives interact first with the mitochondrial compartment affecting cellular metabolism while the plasma membrane is less affected. These differences also suggest that the internalization of the compound is produced before cell membrane damage. Similar behaviour has been described for single and double-chain surfactants from lysine [53] as well as for cationic nanovesicular systems containing lysine-based surfactants [54].

The toxicity showed by these surfactants is lower than those reported for double-chain surfactants from arginine and lysine with a gemini structure [42-43]. However, double chain surfactants from arginine with a glycerolipid structure exhibited lower toxicity possibly due to their lower chemical stability [42]. The chemical bond linking the head group to the two hydrophobic chains can affect toxicity. Glycerolipid surfactants from 
arginine contain two alkyl chains linked to the head group by ester bonds. These ester bonds can be easily hydrolysed giving rise to non-toxic species.

Our results clearly show that the incorporation of the second alkyl chain on LAM increases the cytotoxicity against the 3T3, HaCat and HeLa cell lines. This behaviour contrasts with that observed for the haemolytic activity and indicates that the mechanisms that dominate the interaction of LAM or double-chain derivatives aggregates ( micelles for LAM or vesicles for the double-chain compounds) with red blood cells and the other cell lines are different. These results are in line with previous studies that reported that cytotoxic effects of carrier systems differ depending on the cell lines used due to the nature of these cells [55].

It seems that cytotoxicity slightly decreases by increasing the length of one of the hydrophobic chains. In fact, the lowest cytotoxicity was obtained for the $\mathrm{LANHC}_{18}$. Notice that vesicles formed by this surfactant have the lowest surface cationic charge. Cell membranes have large negatively charged domains. It has been described that cationic vesicles interact with cell membranes neutralizing the sialic acid groups and changing the surface charge from negative to positive [56]. Then, because of electrostatic interactions a great affinity of vesicles with high cationic charge density is expected.

The $\mathrm{IC}_{50}$ values suggest that the aggregate's size does not affect the cytotoxicity against the three cell lines tested. The influence of aggregate's size on cellular toxicity is not clearly explained in the literature. In fact, some researchers have proposed that cells more easily take up smaller particles [57-36] while other studies suggest that the size of nanoparticles does not influence cytotoxicity [58].

In general, dialkyl dimethylammonium bromides with similar alkyl chain lengths showed higher cytotoxicity than these arginine derivatives. For example, the $\mathrm{IC}_{50}$ of $\mathrm{DDAB}$ against erythroleukemic cells was $0.85 \mu \mathrm{M}$ [59]. 
It should be noticed that overall, vesicles formed by pure cationic lipids can exhibit toxicity, but this can be reduced adding another compound to the vesicular system. At $100 \mu \mathrm{M}$ the cell viability of vesicles prepared with pure DODAB (dioctadecyl dimethylammonium bromide), DHDAB (dihexadecyl dimethylammonium bromide) and DMDAB (dimiristoyl dimethylammonium bromide) is about $30 \%, 20 \%$ and $5 \%$ respectively. However, at this same concentration, the cell viability rises up to more than $60 \%$ when the vesicles are formulated with these cationic surfactants together with a neutral phospholipid [60]. The haemolytic activity of negatively charged vesicles prepared with mixtures of diacylglycerol arginine-based surfactants/phosphatidylglycerols was much lower than those prepared with the cationic surfactant alone. ${ }^{61}$ Moreover, it has been reported that cationic niosomes prepared with mixtures of DODAB, DPPC and cholesterol showed very low toxicity against $\mathrm{B}_{16} \mathrm{~F}_{10}$ cell lines $\left(\mathrm{IC}_{50}>3.12 \mathrm{mM}\right)[1 \mathrm{~b}]$. For this reason, studies of the effect of adding neutral phospholipids on cationic vesicles prepared with these surfactants are underway. The aim is to know if this procedure reduces the cellular toxicity of these cationic formulations.

\section{CONCLUSIONS}

Four novel double-chain surfactants with different hydrophobic chain lengths have been prepared from the biocompatible $\mathrm{N}^{\alpha}$-Lauroyl arginine methyl ester (LAM). The synthetic approach used allows for the preparation of these new compounds on a large scale, at a reasonable cost and low ecological impact.

The CAC of these new cationic surfactants is much smaller than that shown by the singlechain homolog LAM. Because of their molecular architecture consisting of one polar head and two alkyl chains, they form cationic vesicles at very low concentrations. Our results indicate that by introducing a second alkyl chain on the single-chain surfactant LAM it is possible to obtain new compounds that form stable cationic vesicles in aqueous solutions 
and present very low haemolytic activity. Moreover, cationic vesicles prepared with the LANHC $_{10}$ also have good antimicrobial activity against Gram-positive bacteria. In vitro studies with 3T3, HaCaT and HeLa cells show that these double arginine surfactants exhibit weaker cytotoxic effects compared to conventional dialkyl dimethylammonium surfactants. These compounds can be suitable candidates to be used in biotechnological and pharmaceutical applications because of both the synthetic procedure required for their preparation as well as their properties. Finally, it should be remarked that understanding the physicochemical properties of the cationic surfactants in association with their biological properties can lead to a rational design of safe cationic lipids.

\section{ACKNOWLEDGEMENTS}

The authors would like to thank the Spanish Plan National I+D+I MAT2012-38047-C0202, MAT2012-38047-C02-01, MIMECO-CTQ2013-41514-P, MIMECO-CTQ201459632-R and the "Grupo de Tensioactivos con Membranas Celulares" (Universitat de Barcelona), Unidad asociada CSIC.

\section{Highlights}

1. Cationic double chain arginine based surfactants have been prepared using a simple and economical synthetic approach.

2. Stable cationic vesicles have been prepared using double chain arginine surfactants.

3. The antimicrobial activity of these cationic vesicles depends on the alkyl chain length of the surfactant. 
4. The low haemolytic activity of vesicles prepared with these double chain derivatives is noteworthy.

\section{TABLES}

Table 1. Details of sample preparation. All solutions have been prepared using $5 \mathrm{~mL}$ of water.

\begin{tabular}{ccccc}
\hline & $\begin{array}{c}\text { LANHC }_{10} \\
(\mathrm{mg})\end{array}$ & $\begin{array}{c}\text { LANHC }_{12} \\
(\mathrm{mg})\end{array}$ & $\begin{array}{c}\text { LANHC }_{14} \\
(\mathrm{mg})\end{array}$ & $\begin{array}{c}\text { LANHC }_{18} \\
(\mathrm{mg})\end{array}$ \\
\hline $1 \mathrm{mM}$ & 2.7 & 2.8 & 2.9 & 3.2 \\
$2.5 \mathrm{mM}$ & 6.7 & 7 & 7.2 & \\
$5 \mathrm{mM}$ & 13.5 & 14 & 14.4 & \\
$10 \mathrm{mM}$ & 27 & 28 & 29 & \\
\hline
\end{tabular}


*Weights measured with $0.01 \mathrm{mg}$ precision. 
Table 2. CAC values obtained by surface tension and conductivity measurements as well as the surface tension at the $\mathrm{CVC}\left(\gamma_{\mathrm{cmc}}\right)$, the effectiveness $(\pi)$ and the area per molecule $\left(\mathrm{A}_{\min }\right)$ for the LAM and the double chain cationic surfactants are shown.

\begin{tabular}{|c|c|c|c|c|c|}
\hline Surfactant & $\begin{array}{c}\mathrm{CAC}^{\mathrm{a}} \\
\text { Conductivity } \\
\mathrm{mM}\end{array}$ & $\begin{array}{c}\mathrm{CAC}^{\mathrm{a}} \\
\text { Surface tension } \\
\mathrm{mM}\end{array}$ & $\begin{array}{l}\gamma_{\mathrm{cmc}}^{\mathrm{b}} \\
\mathrm{mN} / \mathrm{m}\end{array}$ & $\Pi^{\mathrm{b}}$ & $\begin{array}{l}\mathrm{A}_{\min }{ }^{\mathrm{c}} \\
\mathrm{nm}^{2}\end{array}$ \\
\hline $\mathrm{LAM}^{1}$ & $5.4 \pm 0.02$ & $5.8 \pm 0.5$ & $32 \pm 1$ & $40 \pm 1$ & $0.67 \pm 0.21$ \\
\hline $\mathrm{LANHC}_{10}$ & $\begin{array}{c}0.29 \pm 0.02 \\
0.33 \pm 0.02 *\end{array}$ & $0.14 \pm 0.01$ & $24 \pm 1$ & $48 \pm 1$ & $1.02 \pm 0.24$ \\
\hline $\mathrm{LANHC}_{12}$ & $\begin{array}{c}0.12 \pm 0.01 \\
0.13^{*} \pm 0.01\end{array}$ & $0.055 \pm 0.006$ & $24 \pm 1$ & $48 \pm 1$ & $0.65 \pm 0.33$ \\
\hline $\mathrm{LANHC}_{14}$ & $\begin{array}{c}0.080 \pm 0.005 \\
0.090 \pm 0.005 *\end{array}$ & $0.035 \pm 0.003$ & $30 \pm 1$ & $42 \pm 1$ & $0.73 \pm 0.33$ \\
\hline $\mathrm{LANHC}_{18}$ & $\begin{array}{c}---- \\
0.072 \pm 0.004 *\end{array}$ & $0.090 \pm 0.009$ & $28 \pm 1$ & $44 \pm 1$ & $1.04 \pm 0.27$ \\
\hline
\end{tabular}

${ }^{1} \mathrm{CAC}$ value obtained from reference 9

${ }^{*} \mathrm{CAC}$ obtained at $50^{\circ} \mathrm{C}$

${ }^{\text {aThe }} \mathrm{CAC}$ errors correspond to the $95 \%$ confidence interval obtained from the crossing point of two straight lines.

${ }^{\mathrm{b}} \gamma$ and $\Pi$ errors correspond to $95 \%$ confidence intervals determined for the technique.

${ }^{c} A_{\min }$ errors correspond to the $95 \%$ confidence interval obtained from the slope incertitude and error transmission. 
Table 3. Effect of the concentration on the size and stability of vesicles prepared with the arginine surfactants

\begin{tabular}{|c|c|c|c|c|}
\hline & $\mathrm{T}^{\mathrm{a}}$ (으) & Visual aspect and stability & $\begin{array}{l}\text { Populations } \\
\text { (Diameter, nm) }\end{array}$ & Pdl \\
\hline \multirow[t]{2}{*}{$L^{2} A N C_{10} 1 \mathrm{mM}$} & 25 & Bluish solution, Giant vesicles & $4172 \mathrm{~nm}, 94 \mathrm{~nm}$ & \\
\hline & 50 & Bluish translucent & $279 \mathrm{~nm}$ & 0.200 \\
\hline \multirow[t]{2}{*}{$L^{2} A N H C_{10} 2.5 \mathrm{mM}$} & 25 & $\begin{array}{l}\text { Presence of giant vesicles } \\
\text { PRECIPITATION }\end{array}$ & $\begin{array}{l}318 \mathrm{~nm}, 4040 \mathrm{~nm} \\
80 \mathrm{~nm}\end{array}$ & 0.710 \\
\hline & 50 & $\begin{array}{l}\text { Presence of giant vesicles } \\
\text { PRECIPITATION }\end{array}$ & $\begin{array}{l}1590 \mathrm{~nm} \\
167 \mathrm{~nm}\end{array}$ & 0.592 \\
\hline \multirow[t]{2}{*}{$L^{2} N H C_{10} 5 \mathrm{mM}$} & 25 & $\begin{array}{l}\text { Very turbid } \\
\text { Non measurable }\end{array}$ & & \\
\hline & 50 & $\begin{array}{l}\text { Giant vesicles } \\
\text { PRECIPITATION }\end{array}$ & $\begin{array}{l}1302 \mathrm{~nm}, 202 \mathrm{~nm} \\
4893 \mathrm{~nm}\end{array}$ & 0.574 \\
\hline \multirow[t]{2}{*}{$L^{2} A N H C_{10} 10 \mathrm{mM}$} & 25 & $\begin{array}{l}\text { Very turbid, Non measurable } \\
\text { PRECIPITATION }\end{array}$ & & \\
\hline & 50 & $\begin{array}{l}\text { Two populations } \\
\text { PRECIPITATION }\end{array}$ & $\begin{array}{l}1410 \mathrm{~nm} \\
53 \mathrm{~nm}\end{array}$ & 1 \\
\hline \multirow[t]{2}{*}{$L_{A N H C} 12 \mathrm{mM}$} & 25 & $\begin{array}{l}\text { Bluish solution, very dispersed } \\
\text { population with giant aggregates }\end{array}$ & $\begin{array}{l}1419 \mathrm{~nm}, 169 \mathrm{~nm} \\
5212 \mathrm{~nm}\end{array}$ & 0.506 \\
\hline & 50 & Bluish translucent & $306 \mathrm{~nm}$ & 0.194 \\
\hline \multirow[t]{2}{*}{ LANHC $_{12} 2.5 \mathrm{mM}$} & 25 & Bluish solution & $\begin{array}{l}851 \mathrm{~nm} \\
155 \mathrm{~nm}\end{array}$ & 0.521 \\
\hline & 50 & Bluish solution & $185 \mathrm{~nm}$ & 0.376 \\
\hline \multirow[t]{2}{*}{$L_{A N H C} C_{12} 5 \mathrm{mM}$} & 25 & Bluish solution & $\begin{array}{l}1351 \mathrm{~nm}, 152 \mathrm{~nm} \\
4579 \mathrm{~nm}\end{array}$ & 1.0 \\
\hline & 50 & Clear bluish solution & $91.5 \mathrm{~nm}$ & 0.318 \\
\hline \multirow[t]{2}{*}{ LANHC $_{12} 10 \mathrm{mM}$} & 25 & Not measurable & & \\
\hline & 50 & Clear bluish solution & $212 \mathrm{~nm}$ & 0.229 \\
\hline \multirow[t]{2}{*}{$L^{2 A N H C} C_{14} 1 \mathrm{mM}$} & 25 & Bluish solution & $203 \mathrm{~nm}$ & 0.200 \\
\hline & 50 & Bluish translucent & $227 \mathrm{~nm}$ & 0.134 \\
\hline \multirow[t]{2}{*}{$L^{2} \mathrm{NHC}_{14} 2.5 \mathrm{mM}$} & 25 & $\begin{array}{l}\text { Very turbid and bluish solution } \\
\text { Not measurable }\end{array}$ & & \\
\hline & 50 & Bluish translucent & $242 \mathrm{~nm}$ & 0.112 \\
\hline $\mathrm{LANHC}_{14} 5 \mathrm{mM}$ & 25 & $\begin{array}{l}\text { Very turbid and Bluish solution } \\
\text { Not measurable } \\
\text { Bluish solution }\end{array}$ & $176 \mathrm{~nm}$ & 076 \\
\hline \multirow[t]{2}{*}{ LANHC $_{14} 10 \mathrm{mM}$} & 25 & $\begin{array}{l}\text { Very turbid and Bluish solution } \\
\text { Not measurable }\end{array}$ & & \\
\hline & 50 & One population & $203 \mathrm{~nm}$ & 0.113 \\
\hline \multirow[t]{2}{*}{$L^{L A N H C_{18} 1 \mathrm{mM}}$} & 25 & Bluish solution & $60 \mathrm{~nm}$ & \\
\hline & 50 & Bluish translucent & $60 \mathrm{~nm}$ & 0.265 \\
\hline
\end{tabular}

*The size distribution profiles are shown in Figure S1 (Supporting Information) 
Table 4. Antimicrobial activity expressed as minimum inhibitory concentration (MIC) of the double chain arginine based surfactants.

\begin{tabular}{|c|c|c|c|c|c|}
\hline Microorganisms & $\begin{array}{c}\mathbf{L A M}^{\mathbf{1}} \\
(\mu \mathrm{M})\end{array}$ & $\begin{array}{l}\text { LANHC }_{10} \\
(\mu \mathrm{M})\end{array}$ & $\begin{array}{l}\text { LANHC }_{12} \\
(\mu \mathrm{M})\end{array}$ & $\begin{array}{l}\text { LANHC14 } \\
\qquad(\mu \mathrm{M})\end{array}$ & $\begin{array}{c}\text { LANHC }_{18} \\
(\mu \mathrm{M})\end{array}$ \\
\hline M. luteus ATCC 9341 & 19 & 17 & 510 & 243 & $\mathrm{R}$ \\
\hline B. subtilis ATCC 6633 & 19 & $\mathrm{R}$ & $\mathrm{R}$ & 486 & $\mathrm{R}$ \\
\hline S. aureus ATCC 29213 & - & 17 & $\mathrm{R}$ & 486 & $\mathrm{R}$ \\
\hline $\begin{array}{c}\text { S. epidermidis ATCC } \\
12228\end{array}$ & 19 & 17 & 510 & 486 & $\mathrm{R}$ \\
\hline $\begin{array}{c}\text { P. aeruginosa ATCC } \\
27853\end{array}$ & 78 & 68 & $\mathrm{R}$ & $\mathrm{R}$ & $\mathrm{R}$ \\
\hline E. coli ATCC 25922 & 38 & 269 & $\mathrm{R}$ & $\mathrm{R}$ & $\mathrm{R}$ \\
\hline $\begin{array}{c}\text { K. pneumonae ATCC } \\
13883\end{array}$ & 78 & $\mathrm{R}$ & $\mathrm{R}$ & $\mathrm{R}$ & $\mathrm{R}$ \\
\hline C. albicans ATCC 10231 & 19 & 68 & $\mathrm{R}$ & 243 & $\mathrm{R}$ \\
\hline
\end{tabular}

${ }^{1}$ From reference 42

*The MIC determination is a qualitative assay and the estimated error is of the order of magnitude of the value. 
Table 5. Hemolytic activity $\left(\mathrm{HC}_{50}\right)$ and Cytotoxic Effect $\left(\mathrm{IC}_{50}\right)$ of Double Chain Arginine Based-Surfactants.

\begin{tabular}{|c|c|c|c|c|c|c|c|}
\hline \multirow[b]{2}{*}{ Surfactant } & \multirow{2}{*}{$\begin{array}{l}\text { Hemolysis } \\
\mathrm{HC}_{50}(\mu \mathrm{M})\end{array}$} & \multicolumn{2}{|c|}{$3 \mathrm{~T} 3 \mathrm{IC}_{50}(\mu \mathrm{M})$} & \multicolumn{2}{|c|}{$\mathrm{HaCaT} \mathrm{IC}_{50}(\mu \mathrm{M})$} & \multicolumn{2}{|c|}{ HeLa IC $50(\mu \mathrm{M})$} \\
\hline & & NRU & MTT & NRU & MTT & NRU & MTT \\
\hline LAM* $^{*}$ & 144 & 235 & 154 & 238 & 165 & & \\
\hline $\mathrm{LANHC}_{10}$ & $761 \pm 39$ & $34 \pm 9$ & $27 \pm 7$ & $119 \pm 49$ & $21 \pm 12$ & $40 \pm 36$ & $16 \pm 4$ \\
\hline $\mathrm{LANHC}_{12}$ & $708 \pm 214$ & $34 \pm 9.5$ & $12 \pm 4$ & $22 \pm 9$ & $14 \pm 5$ & $112 \pm 124$ & $12 \pm 5$ \\
\hline $\mathrm{LANHC}_{14}$ & $412 \pm 62$ & $30 \pm 10$ & $20 \pm 8$ & $28 \pm 9$ & $23 \pm 10$ & $62 \pm 21$ & $38 \pm 23$ \\
\hline $\mathrm{LANHC}_{18}$ & $139 \pm 56$ & $43 \pm 14$ & $34 \pm 12$ & $44 \pm 20$ & $36 \pm 25$ & --- & $36 \pm 8$ \\
\hline
\end{tabular}

*From reference 42

Results expressed as mean \pm standard error of at least 3 independent experiments 


\section{Figures}

\section{Figure captions}

Figure 1. Chemical procedure for the synthesis of single and double chain arginine surfactants $\left(\mathrm{LANHC}_{\mathrm{x}}, \mathrm{x}\right.$ corresponds to the length of the second alkyl chain).

Figure 2. Conductivity versus concentration curves for the $\mathrm{LANHC}_{14}$ surfactants $\left(\mathbf{E 5}^{\circ} \mathrm{C}, \bullet 50^{\circ} \mathrm{C}\right)$.

Figure 3. Pure surfactant solutions at $25^{\circ} \mathrm{C}$ at three different concentrations $(1,2.5$ and $5 \mathrm{mM}):$ a) LANHC 10 ; b) LANHC 12 ; c) LANHC14. 


\section{Figure 1}

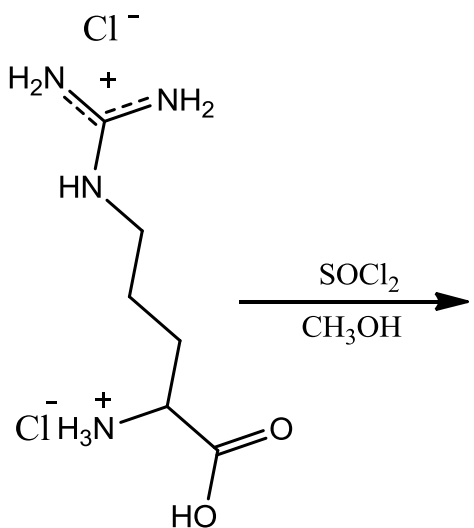

Arginine dihydrochloride<smiles>COC(=O)C(CCCNC(=N)Cl)NC(=O)C1(C)CC1CC1(C)CC1</smiles>

$\mathrm{N}^{\mathrm{a}}$-lauroyl arginine methyl ester hydrochloride (LAM)

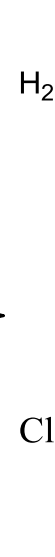

Arginine methyl ester dihydrochloride

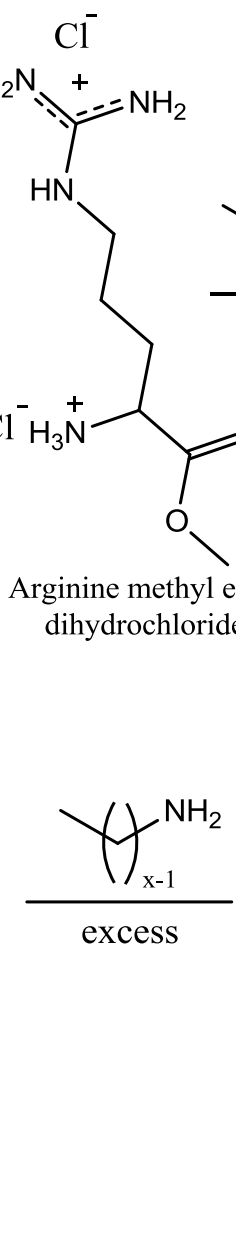

$\mathrm{NaOH}$

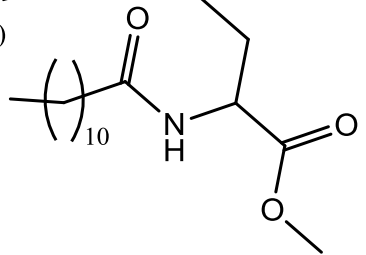

$\mathrm{N}^{\mathrm{a}}$-lauroyl arginine methyl ester hydrochloride

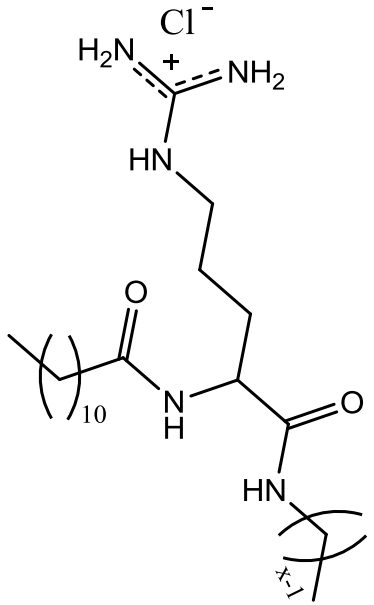

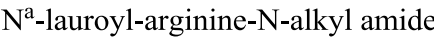
hydrochloride $\left(\mathrm{LANHC}_{\mathrm{x}}\right.$ ) 
Figure 2

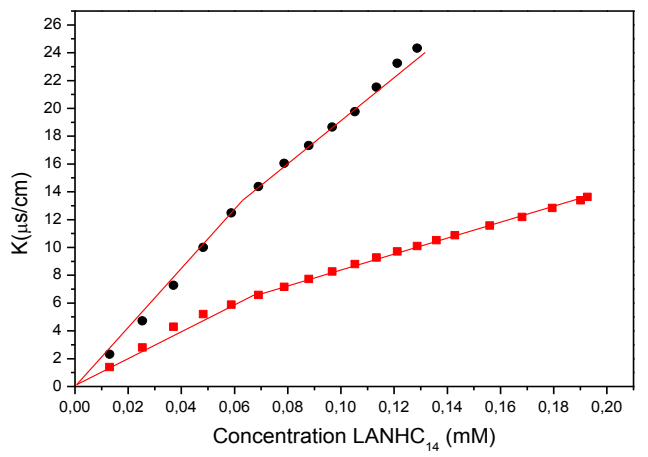




\section{Figure 3}

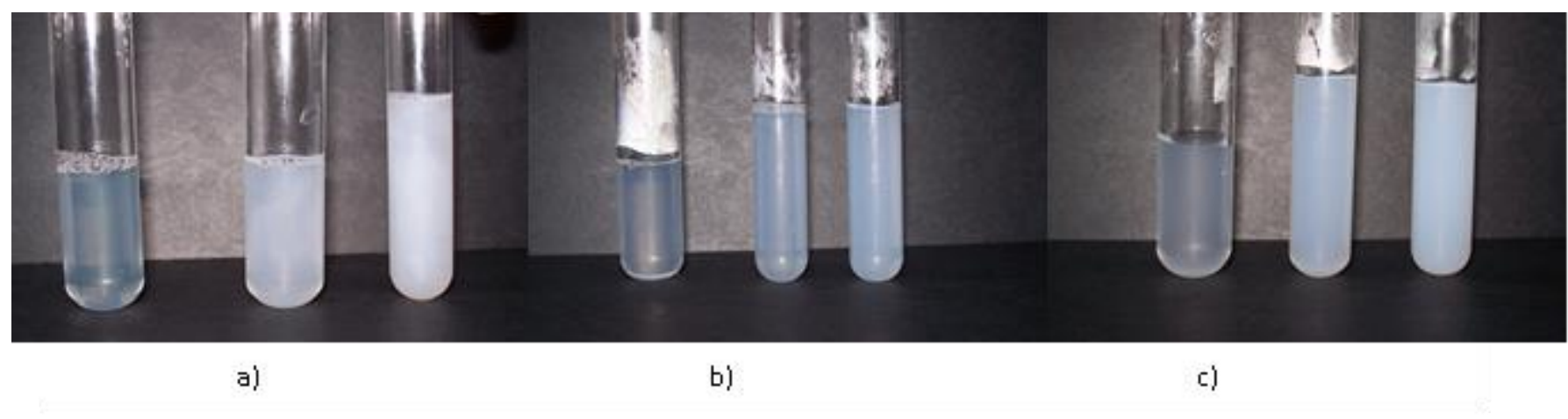

\section{REFERENCES}

[1] (a)L. Pérez, A. Pinazo, R. Pons, M.R. Infante, Advances in Colloid and Interface Science, 205 (2014) 134. (b)A. Manosroi, K. Thathang, R.G. Werner, R. Schubert, R. Peschka-Süss, J. Manosroi, Gene Therapeutics, 58 (2008) 485.

[2] (a)M.A. Llies, W.A. Seitz, B.H. Johnson, E.L. Ezell, A.L. Miller, E.B. Thompson, A.T. Balaban, J. Med. Chem., 49 (2006) 3872. (b)S.M. Vyas, J. Turánek, P. Knötigová, A. Kasná, V. Kvardova, E. Rankin, L. Knutson, H.J. Lehmler, New J. Chem., 30 (2006) 944. (c) J.A. Heyes, D. Nicolescu-Duvaz, R.G. Cooper, C.J. Springer, J. Med. Chem., 45 (2002) 99.

[3] a) JPN Silva, ACN Oliveira, M Lucio, AC Gomes, PJG Coutinho, MECDR Oliveira, Colloids and Surfaces b-Biointerfaces, 121 (2014) 371 b) CL Chan, KK Ewert, RN Majzoub, YK Hwu, KS Liang, C Leal, CR Safinya, Journal of Gene Medicine, 16 (2014) 84.

[4] Z. Drulis-Kawa, A. Dorotkiewicz-Jach, J. Gubernator, ; G. Gula, ; T. Bocer, ; W. Doroszkiewicz, , International journal of pharmaceutics, 367( 2009) 211.

[5] (a) G. Nalecz-Jawecki, E. Granbinska-Sota and P. Narkiewicz, Ecotoxicology and Environmental Safety, 54 (2003) 87. (b) M.T. Garcia, I. Ribosa, T. Guindulian, J. Sanchez-Leal, J. Vives-Rego, Envirom. Pollut., 111 (2001) 169.

[6] N.D. Henderson, A review of the environmental impact and toxic effects of DDAC, Environmental Protection Division, BC Environment, Ministry of Environment, Land and Parks, Victoria, British Columbia, 1992.

[7] F. Ferk, M. Misik, C. Hoelzl, M. Uhl, M. Fuerhacker, B. Grillitsch, W. Parzefall, A. Nersesyan, K. Micieta, T. Grummt, V. Ehrlich, S. Knasmüller, Mutagenesis, 22 (2007) 363.

[8] H. Lv, S. Zhang, B. Wang, S. Cui, J. Yan, J. Controlled Release, 114 (2006) 100.

[9] M.C. Moran, A. Pinazo, L. Perez, P. Clapés, M. Angelet, M.T. García, M.P. Vinardell, M.R. Infante, Green Chemistry, 6 (2004) 233.

[10] A. Sorrenti, O. Illa, R. Pons, R. M. Ortuño, Langmuir, 31 (2015), 9608.

[11] A.S Lawrie, A. Albanyan, R.A. Cardigan, J. Mackie and P. Harrison, Vox Sanguinis, 96 (2009) 206.

[12] S.W. Provencher, Comput. Phys. Commun., 27 (1982) 229. 
[13] J.M. Andrews, Journal of Antimicrobial Chemotherapy, 48 (2001) Suppl. S1, 5-16.

[14] T. Mosmann, J. Immunol. Methods, 65 (1983) 55.

[15] W.J. Pape, U. Pfannenbecker and U. Hoppe, Mol. Toxicol., 1 (1987) 525.

[16] M. R. Infante, L. Pérez;; A. Pinazo, Novel Cationic Surfactants from Arginine. In Novel Surfactants, Preparation, Applications and Biodegradabilily ; Holmberg, K. Second Ed.; Surfactant Science Series; Marcel Dekker: New York, 2003; Vol. 76

[17] F. Goursaud, M. Berchel, J. Guilbot, N. Legros, L. Lemiègre, J. Marcilloux, D. Plusquellec, T. Benvegnu, Green Chemistry, 10 (2008) 310.

[18] L. Pérez, A. Pinazo, M. R. Infante, R. Pons, Journal Physical Chemistry B, 111 (2007) 11379.

[19] J.N. Israelachvili, D.J. Mitchell, B.W. Ninham, J. Chem. Soc. Faraday Trans. 2, 72 (1976) 1525.

[20] V. Vijai, A. Patnaik, Langmuir, 23 (2007) 3523.

[21] (a) A. Pinazo, M. Angelet, R. Pons, M. Lozano, M.R. Infante, L. Pérez, Langmuir, 25(2009), 7803.

(b) L. Pérez, A. Pinazo, P. Vinardell, P. Clapés, M. Angelet, M.R. Infante, New Journal of Chemistry, 26 (2002) 1221.

[22] (a) C. Treiner, A. Makayssi, Langmuir, 8 (1992) 794. (b) M.I. Viseu, M.M. Velazquez, C.S. Campos, I. Garcia-Mateos and S.M..B Costa, Langmuir, 16 (2000) 4882.

[23] A. Caria, O. Regev, A. Khan, J. Colloid. Interface Sci., 200 (1998) 19.

[24] I. Grillo, J. Penfold, I. Tucker, F. Cousin, Langmuir, 25 (2009) 3932.

[25] G. Para, A. Hamerska-Dubra, K. Wilk, P. Warszynski, Colloids and Surfaces A. Physicochem. Eng. Aspects, 383 (2011) 67.

[26] M.J. Rosen, J. T. Kunjappu, Surfactants and Interfacial Phenomena, Fourth Edition, Wiley, New Jersey, 2012.

[27] M. Alvarez Alcalde, A. Jover, F. Meijide, L. Galantini, N. Viorel Pavel, A. Antelo, J. Vazquez Tato, Langmuir, 24 (2008) 6060.

[28] L. Perez, M.R. Infate, M. Angelet, P. Clapes, A. Pinazo, Prog.Colloid.Polym. Sci., 123 (2004) 210.

[29] P.W.M. Van Dijk, B. De Kruijiff, P.A.M. Aarts, A.J. Verkleij, J. De Gier, Biochim. Biophys. Acta, 506 (1978) 18.

[30] Y. Kondo, M. Abe, K. Ogino, H. Uchiyama, E.D. Tucker, J.F. Scamerhorn, S.D.Christian, Colloids and surfaces B Biointerfaces, 1 (1993) 51.

[31] E. Feitosa, J. Jansson and B. Lindman, Chemistry and Physics of lipids, 142 (2006) 128.

[32] E.F. Marques, O. Regev, A. Khan, B. Lindman, Advances in Colloidand Interface Science, 100-102 (1999) 83.

[33] E. Feitosa, G. Karlsson and K. Edwards, Chemistry and Physics of Lipids, 140 (2006) 66.

[34] E. Feitosa and W. Brown, Langmuir, 13 (1997) 4810.

[35] I.M. Cuccovia, E. Feitosa, H. Chaimovich and L. Sepulveda, W. Reed, J. Phys. Chem., 94 (1990) 3722.

[36] L. Tavano, M.R. Infante, M. Abo Riya, A. Pinazo, M.P. Vinardell, M. Mitjans, M.A. Manresa, L. Pérez, Soft Matter, 9 (2013) 306.

[37] D.V. Vieira and A.M. Carmona-Ribeiro, J. Antimicrob. Chemother, 58 (2006) 760.

[38] C. Bombelli, F. Bordi, S. Ferro, L. Giansanti, G. Jori, G. Mancini, C. Mazzuca, D. Monti, F. Ricchelli, S. Sennato and M. Venanzi, Molecular Pharmaceutics, 5 (2008) 672.

[39] Y. Barenholz, C. Bombelli, M.G. Bonicelli, P.D. Profio, L. Giansanti, G. Mancini and F. Pascale, Journal of Colloid and Interface Science, 356 (2011) 46.

[40] E.L. Wu, P.J. Fleming, M.S. Yeom, G. Widmalm, J.B. Klauda, K.G. Fleming, Biophysical Journal, 106 (2014) 2493.

[41] H. Pockel, C. Lenz and M.L. Barjas-Castro, Rev. Bras. Hematol. Hemoter., 33 (2011) 297.

[42] A. Pinazo, L. Pérez, M.R. Infante, M.P. Vinardell, M. Mitjans, M.C. Morán, V. Martinez, in N. L. Jacobs (Ed.), Chemical structure and toxicity in Arginine-based surfactants, Nova Science Publishers, New York, 2011, Chapter 6.

[43] A. Colomer, A. Pinazo, M.A. Manresa, M.P. Vinardell, M. Mitjans, M.R. Infante, L. Pérez, J. Med. Chem., 54 (2011) 989.

[44] S. Kitagawa, M. Kasamaki and F. Hiyama, Chem. Pharm. Bull., 49 (2001) 1155.

[45] M. Rasia, M.I. Spengler, S. Palma, R. Manzo, P. Lo Nostro, D. Allemandi, Clinical Hemorheology and Microcirculation, 36 (2007) 133.

[46] T. Benavides, M. Mitjans, V. Martinez, P. Clapés, M.R. Infante, R.H. Clothier, P. Vinardell, Toxicology, 197 (2004) 229.

[47] S. Roy and P.K. Das, Biotechnol. Bioeng., 100 (2008) 756.

[48] A. Fogt, H. Hagerstrand, B. Isoma, Chem. Biol. Interact., 94 (1995) 147.

[49] F. Tang and J.A. Hughes, J. Controlled Release, 62 (1999) 345. 
[50] M. Dubnickova, M. Bobrowska-Hagerstrand, T. Soderstrom, A. Iglic, H. Hagerstrand, Acta Biochim. Pol., 47 (2000) 651.

[51] H. Nagamune, T. Maeda, K. Ohkura, K. Yamamoto, M. Nakajima, H. Kourai, Toxicology in vitro, 14 (2000) 139.

[52] D.R. Nogueira, M. Mitjans, M.R. Infante, M.P. Vinardell, Int. J. Pharm., 420 (2011) 51.

[53] A. Colomer, A. Pinazo, M.T. García, M. Mitjans, M.P. Vinardell, M.R. Infante, V. Martínez, L. Pérez, Langmuir, 28 (2012) 5900.

[54] D.R. Nogueira, M.C. Morán, M. Mitjans, V. Martínez, L. Pérez, M.P. Vinardell, European Journal of Pharmaceutics and Biopharmaceutics, 83 (2013) 33.

[55] T. Xia, M. Kovochich, M. Liong, J.I. Zink, A.E. Nel, ACS Nano, 2 (2008) 85.

[56] A.M. Carmona-Ribeiro, F. Ortis, R.I. Schumacher, M.C.S. Armelin, Langmuir, 13 (1997) 2215.

[57] K.Y. Win and S.S. Feng, Biomaterials, 26 (2005) 2713.

[58] N. Scholer, C. Olbrich, K. Tabatt, R.H. Müller, H. Hahn, O. Liesenfeld, Int. J. Pharm., 221 (2001) 57.

[59] R. Cortesi, E. Esposito, E. Menegatti, R. Gambari, and C. Nastruzzi, Int. J. of Pharm., 139 (1996) 69.

[60] C-H. Liang, T-H. Chou, Chemistry and Physics of Lipids, 158 (2009) 81.

[61] N. Lozano, L. Pérez, R. Pons, A. Pinazo, Amino Acids, 40 (2011) 721. 